\title{
Study on Compensation for Real Estate Registration Errors
}

\author{
Dibing $\mathrm{Xie}^{1}$, Ming Luo ${ }^{2}$ \\ ${ }^{1}$ Jiangxi College of Applied Technology, Ganzhou, Jiangxi 341000, China \\ ${ }^{2}$ Ganzhou Municipal Bureau of Land and Resources, Ganzhou Jiangxi, 341000, China
}

Keywords: Registration of real estate, Registration error, Compensation

\begin{abstract}
In China's "Property Law", the real estate registration system is a system in which the most basic, and has a very important role in the change of property rights, which can not only ensure the smooth property transaction, but also to further ensure that the people own property Safety. Although China's "Property Law" clearly a way to use registration of immovable property announcement, has also developed into effect the principle of registration, and once an error during the registration of real estate, it will cause serious damage to the corresponding rights holders, So, who is going to compensate them, it becomes necessary to confront and solve problems in the real estate registration. The paper conducts study on the compensation for real estate registration errors, hoping to promote the improvement of real estate registration system.
\end{abstract}

\section{Introduction}

With the rapid development of all sectors of society, so that the scope of the property owned by the people themselves in the constantly expanding, species are relative increase, while land and housing and other real estate location has not changed substantially. Based on this, national laws gradually develop and improve the system for the management of real property in the development process, of which the most important is the real estate registration system. The development and implementation of this system, not only enhances the level of protection of people's property, but also to ensure a convenient and smooth process of property rights transaction. However, the real estate registration error is unavoidable at this stage and denial of the problem, thus enhancing its inquiry, the corresponding human rights protection, is the current stage of the key issues to be resolved.

\section{Effective determination of the responsible party when compensation for real estate registration error}

\section{Analysis of real estate registration error}

\section{Real estate registration}

First, according to China's Property Law clearly stipulates that changes in property rights can be divided into two changes, one is delivered, the other one is registered. Under normal circumstances, changes in the way personal property is used to deliver, and the use of real estate registration mode is changed, which is the real estate registration by the respective right holders or interested party who is to submit the application directly, then by the specialized agency responsible under the law provision processes to their property rights and changes to be recorded, resulting in a corresponding legal effects.

Secondly, the real estate registration own nature, academia different people have their own views and opinions, but the main point at this stage focused on the four areas, one administrative behavior. Second, civil behavior. Third, the proof of behavior. Fourth, public and private property. And these four properties from the perspective of their own discourse has a certain rationality, through further proof is not difficult to find real estate registration this behavior only if public and private property have a more reasonable [1].

Finally, although our country in the "Property Law" clearly a liability when the real estate registration system error occurs, however, for the registration but there are misconceptions given after further requirements, and by the corresponding provisions of other countries and relevant research 
areas You can see, at this stage of the real estate registration misconceptions viewpoint there are three, namely, broad, narrow, compromise. Which, broadly speaking, as long as matters relating to the actual facts in the registration process in the registration book recorded inconsistencies can be classified as registration error; a narrow sense, is that on the basis of valid reasons on registration due to human factors cause registration errors, omissions, etc., which results in the registration document and do not want to practice the phenomenon; From this aspect, it is because the original file is missing, errors, omissions and other phenomena insufficient and the registration process, which results in items mentioned with the actual file does not comply with the phenomenon.

Types of registration errors

First, the lack of registration staff their behavior caused the error. In practical terms, the relevant staff registration of real property registration act itself appears lacking is one cause registration error occurred in most major factors [2]. The root cause of this problem is because of their professional knowledge relating to personnel, operational level, sloppy work period, there is not enough awareness of their own functions, as well as some staff with collusion between the applicant and the intentional infliction of registration errors and many other reasons caused.

Secondly, the applicants and the resulting registration errors. Because of inappropriate behavior, which results in the applicant's own real estate registration error it is also very important one of the reasons, this error usually occurs because the statute under which led to real property changed state. In simple terms, is due to lead to real property law appear to change the behavior of the applicant in accordance with the law for the corresponding application for registration, but because of lack of effectiveness of the legal acts, leaving the contents of the register is described with the actual situation is not the same phenomenon.

\section{Analysis of compensation responsibilities property}

Important subject, and to some extent it also has a direct impact on the registration process, and the registration authority and its staff conduct their own behavior will result in registration accuracy severely affected, registration error if the event, the registration authority should bear what responsibility? The rights of people placed under its own liability for the nature of the problem, etc., all need to be faced and solved. However, China's "Property Law" in the corresponding compensation system has been OK, but did not produce liability for errors organ itself effectively explain the nature, cause the problem in the theory of good practice still exists some controversy.

First, the relevant theory. Because of academia did not have a more unified understanding of the registration error nature of its own liability, so the views of relevant scholars there are some differences, while its after summarizing the main national responsibility, civil liability and the responsibility is unknown and so are several views. State responsibility, some experts believe that the responsibility for the registration authority to bear because of registration errors can be classified into administrative compensation of responsibility, so it is the national responsibility. Civil liability that many scholars believe that this is civil liability, it is because the real estate registration act changed so that civil rights act, coupled to State liability if classified, the amount of compensation is relatively cumbersome procedure, based on the like, from nature on is not conducive to the interests of the victims protection. Responsibility of unknown nature that some scholars believe that the division of responsibilities as well as some of its controversial and requires further be clear, so at this stage should not be divided into national liability [3].

Second, the responsibility of the registration authority. Real Estate Registration organ is our national institutions and departments as part of its own particularity in the presence of the corresponding legal relationship, it can not carry out activities in social law, but also appear in civil activities, and therefore their own laws in both We are able to enjoy the corresponding rights and obligations, and also assume different responsibilities. So you want to registration authorities determined their status, we must first define the legal relationship and the relationship between authorities and the property rights between people, and then carried out to determine its nature in the infringement. In simple terms, that is, to clear two aspects, first, is to determine the behavior of authorities tort tort under normal circumstances, or post-infringement. Secondly, when the real estate 
agency to fulfill the liability, an ordinary civil reparation, or to the country of reparation. In its determination process, not only to the human factors led to a detailed analysis of the infringement and its actual responsibility to assume duties infringement determination, but also on the constituent elements of the infringement determined positions. Through its later study found that the damages caused by the registration authority is to be placed under tort go, at that time because it has a certain particularity, it belongs to the state authorities and the staff of its own tort liability tort duties.

\section{Analysis of constituent elements for determination of registration error compensation responsibility}

\section{Main constituent elements of compensation liability due to authorities' registration errors}

Liability registration authority constituted mainly by the three violations and the fact of damage and the causality of the composition. Here we analyze them specifically:

First, the post violations. When the registration of real estate registration If an error, then the main elements of the registration authority itself to bear tort liability is that this behavior is not only related to the interests of the key reasons causing damage to the interests of their own people, or the registration authority to bear liability for damage Foundation. However, because of the registration authority itself more special nature, so we are talking about violations is duties violations. Tort duties constituted by a variety of characteristics multifaceted nature, such as a particular sex, terms of resistance, illegal, damaging and causality. After registration error is only to meet the above characteristics, the error is the registration error caused by the organ. The duties of the infringement is directly determined by the fault, usually an error in the registration authority, the fault caused by the registration staff mainly in the following two aspects reflect, first, the relevant staff guidance application matters untrue, But its still malicious collusion with the applicant, thus leading to registration errors. Secondly, the corresponding staff perform their own functions performed well or do not comply with the appropriate review of obligations resulting error.

Secondly, the fact of damage. Angle liability for damages resulting from registration errors, the relevant registration staff did not conscientiously perform their own consequences of the damage caused by violations, that is, the corresponding interests of people and the interested parties have to bear the damage. As we all know, real estate is a people's property in a very important part, and its position can not be ignored, and the estate of real estate security system is balance important way to ensure transaction security, once an error occurs, it will make life aspects of people severely affected, such as, led to the loss of real estate ownership, the registration process takes a fee, mortgages and other forms of damage invalid. Also to note is that the damage to registration errors to determine the facts, and then be able to determine the corresponding liability [4].

Finally, the causal relationship. This relationship refers to the consequences of the infringement and it produces contact between the causal relationship arising because of registration errors is relatively complex, and the consequences of causes a certain diversity of different kinds of situations and therefore registration authorities to bear the responsibility also differ and different. This also shows that we must determine the appropriate causal facts depending on the damage, and then determine the corresponding liability.

\section{Main constituent elements of compensation liability due to registration errors caused by applicants}

Since the real estate registration error caused by the applicant itself, we need to have the applicant itself bear the responsibility. Therefore, the applicant of the main elements of the tort liability not only contains an error in the registration authority requirements, but also includes subjective fault. First, tort Normally, during the real estate registration, because the applicant once the registration error caused by its own actions is mainly manifested in two aspects, one, because providing false application materials and lead registration error is occurring, secondly, it is the staff and the corresponding error collusion arising after registration. Second, the fact of damage. Registration error caused by the applicant's own reasons, to a certain extent, there are similarities with the organ 
registration error, but causes the error changed the subject. Third, the causal relationship, in the determination of liability, finds causality is very strict, so there will be targeted to increase the rights of people's own responsibility matrix, increasing the level of sophistication of their right to relief, which led to right people can not get the appropriate compensation. Fourth, the fault. Fault in real estate registration error can be divided into two types, one is intentional acts, one is negligence, so be sure to distinguish and identify these two.

\section{Compensation liability for registration errors}

\section{Commitment responsibility of authorities}

Under normal circumstances, the responsibility of the registration authority would be affected more aspects, such as the nature of liability and responsibility principle and the corresponding areas of responsibility and so on. If you determine that the registration error is caused due to the position of infringement, then it would have the appropriate compensation in accordance with national rules for compensation. Determine the compensation standard is to be specific and detailed scope of their responsibilities, and thus the corresponding amount of compensation as well as calculate the standard determined. Under normal circumstances, in the form of compensation for victims of different circumstances, it can be divided into two ways, namely: To be negotiated, the proceedings. And for compensation for the loss of the starting point, be sure to damage the value of the actual situation to determine, in advance or if it is delayed, will lead to starting a lack of fairness. For registration authority exemption, the agency personnel to perform its own mandate no personal behavior relationships, their behavior and civic registration error caused by force majeure, institutions can be exemption [5].

\section{Commitment responsibility of applicants}

Since the applicant's own reason and cause errors when registration damage the interests of people, constitute the ordinary tort, this part of the damage will require full compensation by the applicant, at the same time, the need to pay attention to is that the evidence for invalid the corresponding amount of compensation is not given to the proposed compensation. The compensation should be based on different criteria to distinguish between the fact of damage, such as punitive damages, reparation and compensation for the complementary nature of the soothing properties and the like. The amount of compensation is in accordance with relevant laws and regulations and the market price for compensation.

\section{Conclusions}

All in all, the real estate registration is one of the effective elements of proof when property rights are changed, it is possible to further determine the actual ownership of real estate, property rights to ensure smooth transactions, and therefore strengthen the research on real estate registration error liability is very important and cannot be ignored of.

\section{References}

[1] Ouyang Fangfang. On China's compensation policy for real estate registration errors. Charming China, 2014(10):299-299.

[2] Liu Zhigang. Applicable laws for real estate registration errors causing damages. Journal of Henan University of Finance and Economics, 2015,30(1):13-21.

[3] Zhan Linling. Analysis on doctrine of liability fixation for teal estate registration error compensatio - In perspective of systematic interpretation. Journal of Anhui Vocational College of Police, 2013,12(1):42-45. 
[4] Chen Sijing, Chen Yaodong. Study on compensation responsibility for real estate registration agency. Guangxi Social Sciences,2015(2):94-98.

[5] Wu Chunqi. Interpretative theory study for real estate registration authorities compensation liability nature.Journal of Yantai University: philosophy and social science edition, 2012,25(1):28-35. 